\title{
SIM BILATERAL COMPARISON ON VOLUME OF SOLIDS BY HYDROSTATIC WEIGHING BETWEEN CENAM-MEXICO AND INMETRO-BRAZIL SIM.7.34-B
}

\author{
Luis O. Becerra ${ }^{1}$, Dalni Malta ${ }^{2}$, Luz. Ma. Centeno ${ }^{1}$, José Julio Pinheiro ${ }^{2}$ \\ 1CENAM, Querétaro, Qro., Mexico, lbecerra@cenam.mx; Icenteno@cenam.mx \\ ${ }^{2}$ INMETRO, Xerém, Duque de Caxias, Rj., Brazil, dsfilho@inmetro.gov.br, \\ iijunior@inmetro.gov.br
}

Abstract: This paper presents the results obtained for a SIM comparison between CENAM-Mexico and INMETRO-Brazil in volume of solids by hydrostatic weighing measurements.

In this work are presented a scheme of measurements, and the systems used by the National Metrology Institutes.

The travelling standards were two spheres made of different materials (stainless steel and glass) with approximated diameter of $15 \mathrm{~mm}$ each.

Keywords: Volume of solids, Solid density, hydrostatic weighing measurements.

\section{INTRODUCTION}

As a mutual agreement between technical contacts of CENAM and INMETRO, it was planned a bilateral comparison of volume of solids measured by the hydrostatic weighing method.

The protocol was agreed in August of 2006 and the measurements were carried out from September to November of 2006.

\section{TRAVELLING STANDARDS}

The travelling standards circulated for this comparison were two spheres with the following characteristics,

Table 1. Data of traveling standards for the bilateral comparison

\begin{tabular}{|l|l|l|}
\hline & $\begin{array}{l}\text { Standard } \\
1\end{array}$ & Standard 2 \\
\hline Shape & Sphere & Sphere \\
\hline Material & Glass & $\begin{array}{l}\text { Stainless } \\
\text { Steel }\end{array}$ \\
\hline Approx. diameter & $15,83 \mathrm{~mm}$ & $15,25 \mathrm{~mm}$ \\
\hline Approx. Mass & $4,96 \mathrm{~g}$ & $15,05 \mathrm{~g}$ \\
\hline $\begin{array}{l}\text { Cubic thermal } \\
\text { expansion }\left(1 \times 10^{-6}\right. \\
\left.\mathrm{K}^{-1}\right)\end{array}$ & $9,9 \pm 0,1$ & $48 \pm 1$ \\
\hline
\end{tabular}

IMEKO TC3 \& TC16 \& TC22 International Conference 27th to 30th November, 2007 
The measurand for this bilateral comparison were the volume at $20^{\circ} \mathrm{C}$ of both spheres. The isothermal compressibility of the spheres was considered negligible for this comparison.

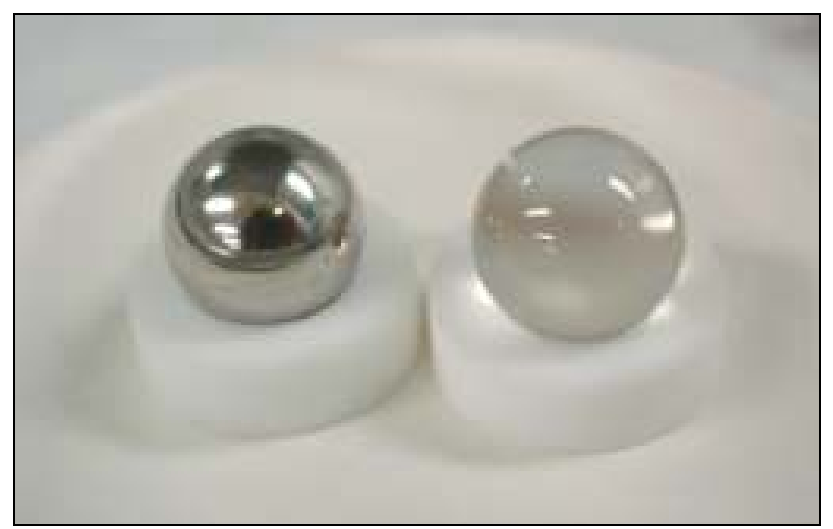

Fig. 1. Travelling standards for this bilateral comparison

\section{HYDROSTATIC WEIGHING SYSTEM}

The measurements were done in hydrostatic weighing systems of the respective NMls. For the measurements there were used the following instruments,

Table 2. Instruments used for the bilateral comparison

\begin{tabular}{|c|c|c|}
\hline & CENAM & INMETRO \\
\hline \multicolumn{3}{|l|}{ Balance } \\
\hline Manufacturer & Mettler & Sartorius \\
\hline Model & AX504 & CC3000 \\
\hline Weighing Range & $504 \mathrm{~g}$ & $3000 \mathrm{~g}$ \\
\hline Resolution & $0,1 \mathrm{mg}$ & $0,1 \mathrm{mg}$ \\
\hline \multicolumn{3}{|l|}{ Mass Standards } \\
\hline Class & OIML E2 & OIML E2 \\
\hline Traceability & CENAM & INMETRO \\
\hline \multicolumn{3}{|l|}{ Density Standard } \\
\hline $\begin{array}{l}\text { Liquid Density } \\
\text { Standard }\end{array}$ & Pentadecane & Water \\
\hline Traceability & CENAM & Formula \\
\hline
\end{tabular}

Due to the small size of the travelling standards used for this bilateral comparison, CENAM had to develop a hydrostatic weighing system in order to make the volume measurements in a controlled temperature, see fig 2. A thermostatic bath was used to circulate cool water in a serpentine placed in the vessel were the measurements were done. A resistance placed in the same vessel was used to keep the temperature controlled. The control of the temperature was done by a Hart Scientific controller. 
In order to keep constant the temperature, INMETRO used a commercial bath Tamson TMVA 70, see fig. 3.

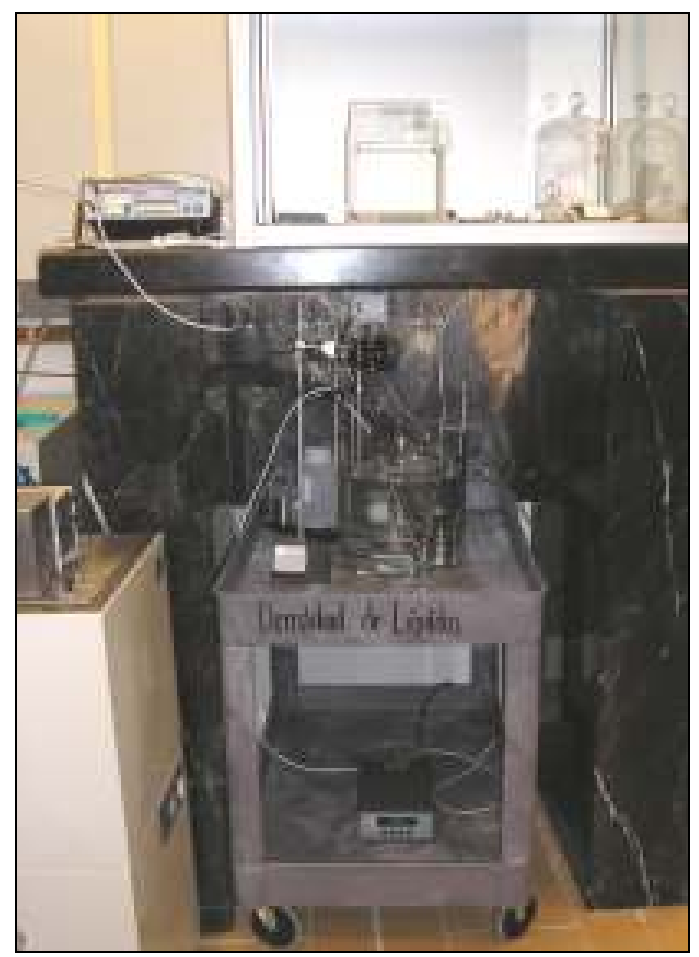

Fig. 2. Hydrostatic weighing system of CENAM. Thermostatic bath implemented by CENAM for this bilateral comparison.

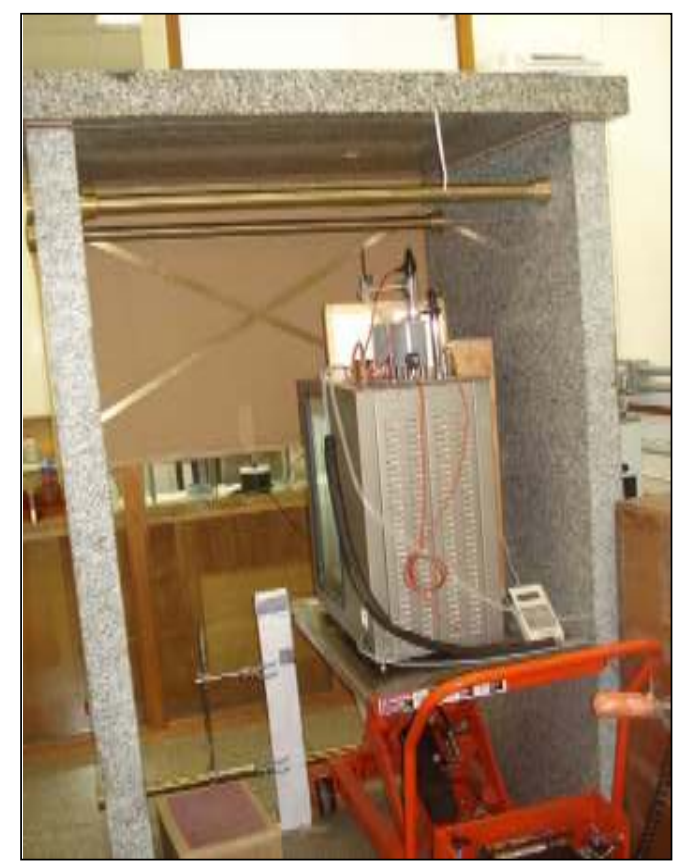

Fig. 3. Hydrostatic weighing system of INMETRO. The balance is placed in the upper part of the tall table. The thermostatic bath is in the middle of the picture. 
Mass measurements (both in air and in liquid) of the spheres were done at CENAM by comparison against mass standards and by direct reading of the balance at INMETRO.

The liquid density standard used by CENAM was Pentadecane $\left(\mathrm{C}_{15} \mathrm{H}_{32}\right)$ calibrated against CENAM's solid density standards Z-01 and Z-02 (zerodur spheres of $1 \mathrm{~kg}$ approximately).

Z-01 and Z-02 are the Mexican Density standards whose density values are traceable to PTB-Germany.

INMETRO used pure water as liquid density standard and density of water was calculated by Tanaka's formula [1].

\section{SCHEME OF MEASUREMENTS AND MATHEMATICAL MODEL USED FOR THE LABORATORIES}

The volume of the spheres were measured at INMETRO in September 2006 and then at CENAM in November 2006.

Each laboratory made the measurements using their own hydrostatic weighing system and procedures.

The mathematical model used for CENAM for the calculation of the volume of the spheres was the following,

$$
V_{O}\left(20^{\circ} C\right)=\frac{m_{m s 1}-m_{m s 2}-\rho_{a}\left(V_{m s 1}-V_{m s 2}\right)+\Delta m_{1} S b_{1}^{-1}-\Delta m_{2} S b_{2}^{-1}+G c_{1}-G c_{2}}{\rho_{L}\left[1+\alpha \cdot\left(20-t_{L}\right)\right]-\rho_{a}\left[1+\alpha \cdot\left(20-t_{a}\right)\right]}
$$

where,

$V_{O}\left(20^{\circ} \mathrm{C}\right) \quad$ is the volume of the sphere at $20^{\circ} \mathrm{C}$

$m_{m s 1} \quad$ is the mass of the mass standard used for the weighing in air

$m_{m s 2} \quad$ is the mass of the mass standard used for the weighing in liquid

$\rho_{a} \quad$ is the air density calculated by CIPM formula [2]

$\rho_{L} \quad$ is the density of the liquid used as standard

$V_{m s(2)} \quad$ is the volume of the mass standard used for the weighing in air (liquid)

$\Delta m_{1(2)} \quad$ is the mass difference between the sphere and the mass standard for the weighing in air (liquid)

$S b_{1(2)}^{-1} \quad$ is the inverse of the sensitivity of the balance for the weighing in air (liquid)

$G c_{1(2)} \quad$ is the gravity correction due to the high difference between the gravity centre of the sphere and the gravity centre of the mass standard for the weighing in air (liquid) 
The mathematical model used for INMETRO for the calculation of the volume of the travelling standards was the following,

$$
V_{O}\left(20^{\circ} C\right)=\frac{\left[M_{O 1}-M_{O 2} \cdot\left(1-\frac{\rho_{a}}{\rho_{b}}\right)\right] \cdot\left[1+\alpha \cdot\left(20-t_{O}\right)\right]}{\rho_{L}\left[1+\alpha_{L} \cdot\left(20-t_{L}\right)\right]}
$$

$V_{O}\left(20^{\circ} \mathrm{C}\right) \quad$ is the volume of the sphere at $20^{\circ} \mathrm{C}$

$M_{O 1} \quad$ is the mass of the travelling standard

$M_{O 2} \quad$ is the "apparent" mass of the travelling standard for the weighing in water

$\rho_{a} \quad$ is the air density

$\rho_{b} \quad$ is the density of the weights used for the balance adjusting/calibration

$\rho_{L} \quad$ is the density of the water calculated by Tanaka's formula

$t_{L} \quad$ is the liquid temperature

$t_{O} \quad$ is the temperature of the travelling standard

$\alpha \quad$ is the cubic thermal expansion coefficient of the travelling standard

$\alpha_{L} \quad$ is the cubic thermal expansion coefficient of the water

The Evaluation of the uncertainties associated to the measurements results reported by both National Metrology Institutes was done by GUM's Method [3].

\section{RESULTS OF THE EXPERIMENTS}

The volume of the spheres reported by the participant institutes are in table 3 .

Table 3. Results reported by the participant laboratories

\begin{tabular}{|l|c|c|c|c|}
\hline & \multicolumn{2}{|c|}{ Glass Sphere } & \multicolumn{2}{c|}{ Stainless Steel Sphere } \\
\hline & $\begin{array}{c}V_{o}\left(20^{\circ} \mathrm{C}\right) \\
\left(\mathrm{cm}^{3}\right)\end{array}$ & $\begin{array}{c}\mathrm{U}, \mathrm{k}=2 \\
\left(\mathrm{~cm}^{3}\right)\end{array}$ & $\begin{array}{c}V_{o}\left(20^{\circ} \mathrm{C}\right) \\
\left(\mathrm{cm}^{3}\right)\end{array}$ & $\begin{array}{c}\mathrm{U}, \mathrm{k}=2 \\
\left(\mathrm{~cm}^{3}\right)\end{array}$ \\
\hline CENAM & 2,07652 & 0,00062 & 1,85809 & 0,00050 \\
\hline INMETRO & 2,07670 & 0,00040 & 1,85850 & 0,00040 \\
\hline
\end{tabular}


The absolute difference of the reported volumes $V_{\text {diff }}$ and the expanded uncertainty of such differences $U\left(V_{\text {diff }}\right)$ are reported in table 4.

$$
\begin{gathered}
V_{\text {diff }}=\left|V_{\text {CENAM }}-V_{\text {INMETRO }}\right| \\
U\left(V_{\text {diff }}\right)=\sqrt{U\left(V_{\text {CENAM }}\right)^{2}+U\left(V_{\text {INMETRO }}\right)^{2}}
\end{gathered}
$$

Where,

$V_{i} \quad$ is volume reported by the participants

$U\left(V_{i}\right) \quad$ is expanded uncertainty of the volume reported by the participants

The consistency within the reported results of both laboratories was analyzed by the normalized error criterion $E_{n}$ [4]. Normalized errors evaluated are reported in table 4 .

$$
E_{n}=\frac{\left|V_{\text {CENAM }}-V_{\text {INMETRO }}\right|}{\sqrt{U\left(V_{\text {CENAM }}\right)^{2}-U\left(V_{\text {INMETRO }}\right)^{2}}}
$$

The criterion for the normalized error is the following,

$E_{n} \leq 1$ values reported by participant institutes are consistent $E_{n}>1$ values reported by participant institutes are not consistent

Table 4. Differences of volume, expanded uncertainties of these differences and normalized errors

\begin{tabular}{|l|l|l|l|}
\hline & $\begin{array}{l}V_{\text {diff }} \\
\left(\mathrm{cm}^{3}\right)\end{array}$ & $\begin{array}{l}U\left(V_{\text {diff }}\right), \mathrm{k}=2 \\
\left(\mathrm{~cm}^{3}\right)\end{array}$ & $E_{n}$ \\
\hline Glass Sphere & 0,00018 & 0,00074 & 0,24 \\
\hline Stainless Steel Sphere & 0,00041 & 0,00064 & 0,64 \\
\hline
\end{tabular}

Figure 4. Graph of the volume of the sphere of glass reported by participant laboratories 


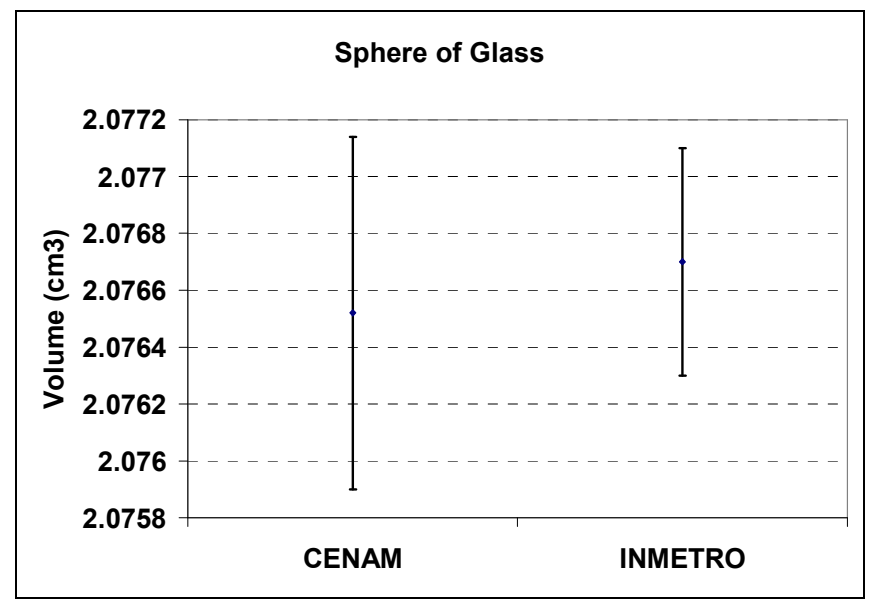

Figure 5. Graph of the volume of the sphere of stainless steel reported by participant laboratories

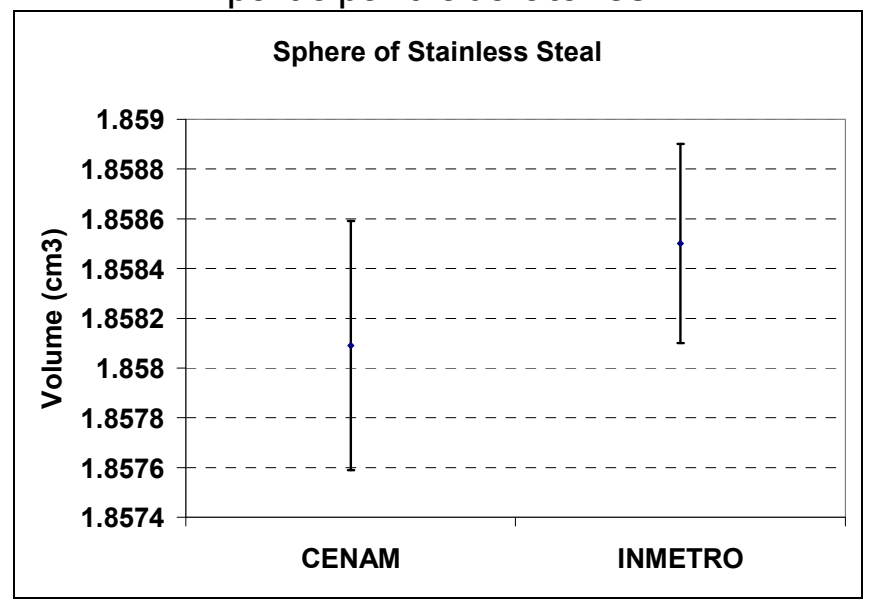

\section{CONCLUSIONS}

This bilateral comparison presented a special problem to participant laboratories due to the small size of the travelling standards circulated.

The normalized errors of table 4 show that volumes of the spheres reported by participant laboratories measured by hydrostatic weighing method are consistent.

\section{Acknowledgements}

The authors thank to A. Daued and L. M. Peña by their great support in the development of the hydrostatic weighing system at CENAM in order to measure the travelling standards used in this bilateral comparison. The hydrostatic weighing system of CENAM is normally used for spheres of approx. $10 \mathrm{~cm}$ of diameter (Zerodur spheres of approx. $1 \mathrm{~kg}$ of mass). 


\section{REFERENCES}

[1] M. Tanaka, G. Girard, R. Davis, A. Peuto and N. Bignell, Recommended table for the density of water between $0{ }^{\circ} \mathrm{C}$ and $40{ }^{\circ} \mathrm{C}$ based on recent experimental reports, Metrología, Vol. 38, 2001, 301-309.

[2] R. S. Davis., "Equation for the determination of the density of moist air", (1981/91) METROLOGIA 1992, 29, 67-70

[3] BIPM, IEC, IFCC, ISO, IUPAC, IUPAP, OIML "Guide to the expression of uncertainty in measurement", Reprinted in 1995.

[4] Wolfang Wöger -Remarks on the En - Criterion Used in Measurement Comparison, PTB Mitteilingen 109 1/99, Internationale Zusammenarbeit 